\title{
A QUESTIONADA JUSTIÇA DO TRABALHO
}

\section{ARNALDO SÜSSEKIND*}

É notório que se questiona, presentemente, a eficácia e a própria validade da Justiça do Trabalho, na dissonante orquestração dos que pretendem o enfraquecimento do Poder Judiciário e dos que advogam a desregulamentação do Direito do Trabalho.

Essa desregulamentação - e não a justificável flexibilização de algumas normas, sob tutela sindical, para atender a peculiaridades regionais, empresariais ou profissionais - tem por alvo a prevalência da autonomia privada, individual e coletiva, na estipulação das condições de trabalho. Seria a volta ao laisser faire.

A autonomia privada coletiva só tem tido razoável êxito nos países em que a organização sindical é capaz de obter, pelos instrumentos da negociação coletiva, adequadas condições de trabalho.

O Brasil, com quase setenta anos de proteção legal aos trabalhadores e tradição jurídica romano-germânica do direito escrito, ainda é um país desigualmente desenvolvido, com sindicatos expressivos apenas em algumas regiões e categorias, razão porque torna-se imprescindível um ordenamento legal constituído de normas gerais indisponíveis, abaixo das quais não se concebe a dignidade do ser humano, que é um dos fundamentos do Estado democrático de direito (Art. 1º , III, da Constituição). Acima desse nível intransacionável é que devem atuar os acordos e convenções coletivas de trabalho, o regulamento de empresa e o próprio contrato invidual do trabalho.

É imperioso considerar, demais disto, que funciona em nosso País uma jurisdição especializada para a solução dos litígios trabalhistas, competente para restaurar ou compensar a eventual violação de direitos e rever condições de trabalho que se tornaram injustas ou inadequadas. A extinção dessa Justiça seria o paraíso para os maus empregadores, cuja conduta já enseja mais de um milhão de reclamações por ano. A legislação pertinente deve ser revista, com ênfase para a criação de órgãos de conciliação e mediação; nunca, porém, revogada.

A Justiça do Trabalho foi instalada a $1^{\circ}$ de maio de 1941, vinculada, administrativamente, ao Ministério do Trabalho, Indústria Comércio. A Constituição de 1946

* Ministro aposentado do TST e titular da Academia Brasileira de Letras Jurídicas. 
integrou os seus órgãos no Poder Judiciário, com a competência de instituir ou rever condições de trabalho nos processos de dissídios coletivos, isto é, com o chamado "poder normativo", que, no dizer do internacionalmente conceituado Plá Rodriguez, nada mais é do que uma forma de arbitragem compulsória institucionalizada num tribunal ("A solução dos conflitos trabalhistas", SP, trad. de Wagner Giglio, p. 25).

As constituições de $1967 / 69$ e 1988 mantiveram a competência da Justiça do Trabalho, inclusive para os dissídios coletivos, sendo que a vigente facultou às partes conflitantes escolherem, por consenso, a via da arbitragem.

Apesar do gigantismo da organização judiciária do trabalho, composta de 1.092 Juntas de Conciliação e Julgamento, 24 Tribunais Regionais e o Tribunal Superior do Trabalho, os processos que percorrem os três graus de jurisdição consomem, em média, seis anos para o trânsito em julgado da decisão. E não há recursos financeiros nem humanos para ampliá-la, sendo certo que cerca de dois mil cargos de Juízes estão vagos nas diferentes jurisdições, porque, salvo honrosas exceções, os baixos vencimentos, em contraste com o excesso de trabalho, não motivam os mais capazes para o ingresso na magistratura. No último concurso para Juiz do Trabalho, terminado em fevereiro deste ano, foram aprovadas somente duas candidatas para quarenta e nove vagas então existentes no Estado do Rio de Janeiro.

O retardamento da solução das ações trabalhistas - e a Justiça do Trabalho não é a mais lenta - pode ser explicado pelo impressionante crescimento do número de processos nela ajuizado: a) década de $60-3.333 .214$; b) década de $70-$ 4.827.884; c) década de $80-8.911 .179$; d) 1990 a $1998-15.473 .880$. Só em 1998, a Justiça do Trabalho recebeu 2.349.419 ações e solucionou 2.233.912.

O Tribunal Superior do Trabalho, a quem cabe uniformizar a jurisprudência e orientar as decisões normativas, impedindo que a mesma norma jurídica seja aplicada diferentemente em cada Estado, julgou em 1998 mais de 112 mil processos, isto é, cada uma das suas cinco turmas, constituídas de cinco ministros, julgou 22.400 processos, o que totaliza, excluídos períodos de férias, mais de 400 processos por mês para cada Ministro. Será possível exigir-se mais?

Diversas são as causas da hipertrofia da Justiça do Trabalho:

$1^{\text {g) }}$ desemprego crescente $(7,71 \%$, atualmente) e alta rotatividade da mão-deobra. Quase todos os trabalhadores despedidos têm algo a reclamar;

$2^{\mathrm{a}}$ ) - extensão da legislação do trabalho aos rurais e domésticos;

$\left.3^{\circ}\right)$ - excesso de empregados não registrados;

$\left.4^{\mathfrak{Q}}\right)$ abuso de contratos simulados (terceirização e cooperativas com os prestadores de serviço trabalhando sob o poder de comando da empresa contratante), visando a encobrir verdadeiras relações de emprego;

$\left.5^{\circ}\right)$ falta de procedimentos prévios de conciliação e mediação para os litígios individuais e coletivos de trabalho;

$\left.6^{\circ}\right)$ cultura desfavorável à mediação e à arbitragem dos conflitos coletivos, que não se altera em virtude da facilidade na instauração da instância judiciária;

$7^{\circ}$ ) complexas regras processuais, com demasiados recursos e depósito insuficiente para o empregador recorrer; 
$\left.8^{\circ}\right)$ excesso de leis e medidas provisórias inovando ou modificando substancialmente o ordenamento legal, muitas vezes com afronta ao bom Direito.

O ideal seria a remoção de todas as concausas. Duas delas, no entanto, poderiam ser focalizadas desde logo; uma por lei, outra por emenda constitucional.

Os litígios individuais, em sua maioria, poderão ser resolvidos no âmbito empresarial, por acordo mediado por comissões paritárias de conciliação, obrigatoriamente criadas nos estabelecimentos de médio ou grande porte. Por seu turno, convenções coletivas firmadas por sindicatos patronais e de trabalhadores instituiriam tais comissões para a mediação dos litígios relativos aos estabelecimentos de menos de 60 empregados. Esses órgãos, que não têm competência para julgar, funcionam exitosamente em diversos países, inclusive nos inúmeros que possuem tribunais de trabalho, como pré-fase obrigatória da distribuição da ação judicial. $O$ professor Klaus Adomeid, catedrático de Direito do Trabalho na Universidade de Berlim, informou-me que mais de dois terços dos casos são resolvidos, por acordo ou desistência, por essas comissões, reduzindo, assim, o número de ações ajuizadas nos tribunais de trabalho da Alemanha, cuja organização, com os três graus de jurisdição, é similar da nossa Justiça do Trabalho.

Em 1982 a Academia Nacional de Direito do Trabalho encarregou-me, juntamente com os saudosos juristas Segadas Vianna e Haddock Lobo, de redigir anteprojeto de lei nesse sentido, cujo texto foi encaminhado ao Congresso Nacional e ao Ministro do Trabalho. Em nenhum desses órgãos foi considerado, apesar das manifestações favoráveis do Fórum Brasileiro da Justiçado Trabalho (Gramado, 1984) e do Seminário de Direito Constitucional do Trabalho (São Paulo, 1992). Em 1994, o ilustre Ministro Marcelo Pimentel promoveu o encaminhamento de projeto de lei ao Congresso Nacional, baseado no texto elaborado pela referida Academia; mas ampliou e formalizou demasiadamente o procedimento, que deve ser simples e o mais informal possível. Por isso mesmo, resolvi atualizar o anteprojeto da Academia e o apresentei à Comissão Permanente de Direito Social do Ministério do Trabalho, que o aprovou por unanimidade e encaminhou, sem sucesso, ao Ministro Paulo Paiva. Afinal, o Presidente Fernando Henrique Cardoso submeteu ao Congresso Nacional projeto similar, que não reduzirá, como se pretende, o volume de processos na Justiça do Trabalho, porquanto determina a homologação dos acordos pelo Juiz do Trabalho, ao invés de respeitar o ajuste firmado sob a supervisão da Comissão Paritária de Conciliação.

Pelo referido anteprojeto da Academia, seria obrigatório o funcionamento de uma comissão paritária de conciliação nas empresas cujos estabelecimentos totalizassem, no mesmo Município, mais de 60 empregados. Essas comissões teriam um membro designado pelo empregador e um eleito pelos empregados. Dois seriam os representantes de cada classe quando houvesse mais de 120 empregados. Haveria um suplente para cada membro da comissão, assegurado aos empregados eleitos o direito à estabilidade no emprego, para assegurar-lhes independência no desempenho dos mandatos, fixados em três anos. As comissões teriam o prazo improrrogável de quinze dias para intentarem a conciliação em procedimento absolutamente informal. Obtida a conciliação, o respectivo termo, firmado perante a comissão, valeria como transação extrajudicial, quitando todos os direitos dele constantes. Se não cumprido 


\section{O Direito do Consumidor na Era da Globalização}

Sônia Maria Vieira de Mello

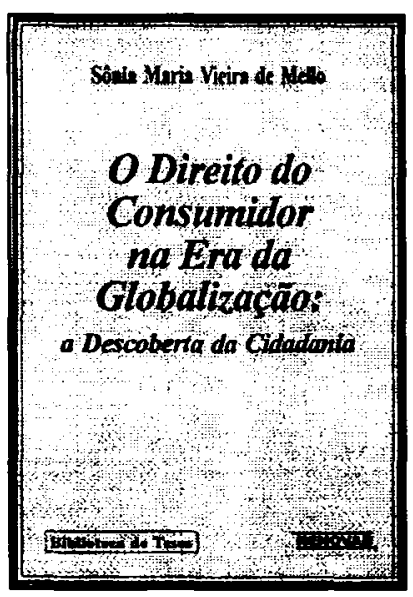

Neste livro, a autora expõe como o consumidor, diante desta era de produção global, de economia de mercado está consideravelmente vulnerável diante das práticas perpetuadas pelos fornecedores de bens e serviços, muito mais bem informados, fundamentados e assessorados, para os embates mercadológicos.

Ref. 0180

Form. 14x21

172 págs.

1998

\section{O Ministério Público Brasileiro}

\section{João Francisco Sauwen Filho}

Desde a retrospectiva histórica até a análise das características da instituição na atualidade, a tese mantém sempre acentuado espírito crítico e a preocupaçāo de ser nāo meramente um trabalho informativo, mas uma avaliação do papel desempenhado pelo Ministério Público no contexto das demais instituiçōes políticas em todas as épocas. A atualidade da instituição é examinada à luz dos documentos mais expressivos da própria consciência da classe, como a Carta de Curitiba, as teses aprovadas no $V^{\circ}$ Congresso Nacional do Ministério Público e as respostas ao questionário elaborado pela CONAMP.

Ref. 0200

Brochura

Form. 13,5x21

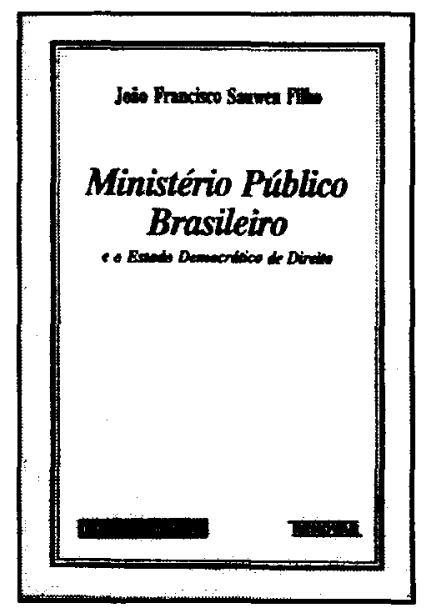

